\title{
A framework to build capacity for a reflex-testing program for Lynch syndrome
}

\author{
Vanessa N. Palter, MD PhD ${ }^{1}$, Natalie A. Baker, MSc ${ }^{1,2}$, Linda Rabeneck, MD, MPH ${ }^{3}$, \\ Jill Tinmouth, MD, PhD ${ }^{2,4}$, Anna R. Gagliardi, $\mathrm{PhD}^{5}$, Erin D. Kennedy, MD, PhD ${ }^{2,6}$, \\ June C. Carroll, MD ${ }^{2,6}$, Steven Gallinger, MD $^{2,7}$ and Nancy N. Baxter, MD PhD ${ }^{1,2}$
}

\begin{abstract}
Purpose: Lynch syndrome (LS) is the most common inherited cause of colorectal cancer. Although testing all colorectal tumors for LS is recommended, the uptake of reflex-testing programs within health systems has been limited. This multipronged study describes the design of a provincial program for reflex testing in Ontario, Canada.
\end{abstract}

Methods: We recruited key stakeholders to participate in qualitative interviews to explore the barriers and facilitators to the implementation of a reflex-testing program. Data were analyzed in an iterative manner, key themes identified, and a framework for a proposed program developed.

Results: Twenty-six key informants participated in our interviews, and several themes were identified. These included providing education for stakeholders (patients, primary care providers, surgeons); challenges with sustaining various resources (laboratory costs, increased workload for pathologists); ensuring consistency of reporting test results; and developing a plan to measure program success. Using these themes, a framework for the reflex-testing program was developed. At a subsequent stakeholder meeting, the framework was refined, and recommendations were identified.

Conclusions: This study identifies factors to ensure the effective implementation of a population-level program for reflex LS testing. The final product is a prototype that can be utilized in other jurisdictions, taking into account local environmental considerations.

Genetics in Medicine (2019) 21:1381-1389; https:/doi.org/10.1038/s41436018-0342-8

Keywords: Lynch syndrome; reflex testing; cancer prevention; screening

\section{INTRODUCTION}

Colorectal cancer (CRC) is the third most common cancer in the world, and the second most common cancer in Canada. ${ }^{1}$ Although the majority of CRC cases are sporadic, Lynch syndrome (LS) is the most common heritable cause of CRC accounting for between $3 \%$ and $5 \%$ of all cases. ${ }^{2}$ Not only does LS increase the risk of CRC, it also increases the risk of endometrial cancer, as well as numerous other malignancies, and is one of the most common inherited forms of cancer of any type. ${ }^{3,4}$

Traditionally, cases of LS were identified using family history criteria; however, relying only on family history can miss up to $68 \%$ of individuals with LS, thus limiting the ability to identify and reduce the risk of CRC in LS carriers. ${ }^{5}$ Fortunately, "reflex testing" the tumors of patients with CRC for mismatch repair (MMR) deficiency using either microsatellite instability (MSI) or immunohistochemistry (IHC) has a greater than $90 \%$ sensitivity to identify possible cases of
LS. $^{6-8}$ As such, almost a decade ago, the Evaluation of Genomic Applications in Practice and Prevention recommended that all patients with CRC undergo this type of reflex tumor-based testing for LS, where the surgical specimens of CRC patients are reflexively tested for LS. ${ }^{9}$

To date, however, there has been variable uptake of reflex testing within health-care systems and organizations, with only $15 \%$ of community hospital cancer programs in the United States having an organized approach to reflex LS testing. Currently only $28 \%$ of patients with CRC in the United States undergo MMR testing. ${ }^{10,11}$ Barriers to implementing reflex testing include a lack of health-care provider education, a paucity of information on how to implement testing, a lack of a clear plan for quality assurance and program evaluation, and the cost of implementation..$^{10,12,13}$ Although these studies provide valuable context for some of the difficulties with initiating reflex testing, many are singleinstitution studies, or are limited to the United States. This

\footnotetext{
${ }^{1}$ St. Michael's Hospital, Toronto, ON, Canada; ${ }^{2}$ Public Health Sciences, University of Toronto, Toronto, ON, Canada; ${ }^{3}$ Cancer Care Ontario, Toronto, ON, Canada; ${ }^{4}$ Sunnybrook Health Sciences Centre, Toronto, ON, Canada; ${ }^{5}$ Toronto General Research Institute, Toronto, ON, Canada; ${ }^{6}$ Mount Sinai Hospital, Toronto, ON, Canada; ${ }^{7}$ Department of Surgery, University Health Network, Toronto, ON, Canada. Correspondence: Vanessa N. Palter (vanessa.palter@mail.utoronto.ca)
} 
notwithstanding, several population or system-wide LS reflextesting programs have been successfully initiated in a number of jurisdictions, including programs in southern California, Ohio, Utah, Pennsylvania, Australia, and Manitoba, Canada. ${ }^{14}$ Of these programs, however, few are national, provincial, or statewide in scope.

The province of Ontario, in Canada, has one of the highest rates of CRC in the world, yet currently there is no population-based program for LS screening. ${ }^{15}$ The current approach in Ontario relies on risk stratification by individual clinicians, and many patients with LS are not identified. This ad hoc approach is unlikely to be effective in reducing the risk of CRC associated with LS carriers or their relatives. The purpose of this study is to explore barriers and facilitators relating to the implementation of reflex LS testing in Ontario, and to develop a prototype for a reflex LS screening program.

\section{Approach}

\section{MATERIALS AND METHODS}

We conducted a qualitative study designed to explore the barriers and facilitators to the implementation of programmatic reflex testing in Ontario. These data were then used to construct a proposed program for reflex LS testing using a pragmatic, descriptive, thematic approach. Research Ethics Board Approval for this study was obtained from St. Michael's Hospital in Toronto, Canada, and informed consent was obtained from all study participants.

\section{Recruitment and participants}

We recruited opinion leaders and stakeholders to participate in qualitative interviews. A purposeful, role-based sampling technique was utilized with participants being deliberately recruited for their role, their specialty, or their previous experience with a high-risk screening program. ${ }^{16,17}$ Specific roles and organizations that we recruited from included geneticists, genetic counselors, oncologists, pathologists, surgeons, policy-makers, representatives from not-for-profit advocacy organizations, and representatives from the High Risk Ontario Breast Screening Program. A standardized email invitation to participate was sent to all identified potential participants, with a reminder email sent out a week later to nonresponders.

\section{Data collection}

Interviews were conducted both in person and over the telephone by a trained qualitative interviewer (N.A.B.) between April 2015 and March 2016. All interviews were semistructured, with recruitment of participants continuing in an iterative fashion until data saturation was complete. ${ }^{18,19}$ The interview guide (Appendix 1) was informed from previous work investigating the barriers and facilitators relating to the organization of reflex-screening LS programs worldwide. $^{20}$ Usability testing of the interview guide was completed with four key informants associated with the study team to assess face and content validity. Based on usability testing, the content of the guide was left largely unchanged; however, the order and wording of questions were altered to improve clarity and flow of the interviews. Key components of the interview guide included (1) exploring barriers and facilitators to implementing reflex LS testing in Ontario, and (2) identifying specific resource requirements and capacity required to deliver such a program. Interviews lasted approximately 30-60 minutes and were audio-recorded, transcribed verbatim by an experienced transcriptionist, and checked for accuracy. In addition, we conducted one focus group specifically for surgeons in April 2015. We took a pragmatic, convenience-based approach and recruited members of this focus group among attendees at a conference.

\section{Data analysis}

In keeping with qualitative research, data collection was concurrent to data analysis in an iterative manner. ${ }^{21} \mathrm{~A}$ thematic analysis was conducted and we followed the six phases of analysis outlined by Braun and Clarke. ${ }^{22}$ Patterns and themes were identified and coded from the transcripts, as well as from the original research aims, and guided by the interview questions, thus drawing on best practices in grounded theory methodology, and making the approach both inductive and deductive in nature. ${ }^{23-25}$ NVivo (version 9), a qualitative data management software program, was used for data management and organization. Techniques to ensure rigor included a checking and questioning process whereby analysts compared codes, sought alternative interpretations or explanations, and tracked interpretive coherence. ${ }^{25,26}$

\section{Creation of proposed program for reflex LS testing in Ontario}

We compared and triangulated key themes identified in the interviews with the themes previously identified in our work assessing the existing LS reflex programs worldwide. ${ }^{20} \mathrm{We}$ then used this information to create a proposed program for reflex LS testing in Ontario.

The framework of this program was then further refined during a one-day stakeholder meeting. Representatives from relevant medical specialties (surgery, gastroenterology, pathology, radiology, gynecology, primary care, public health) across all geographic regions of Ontario, national advocacy organizations, national and provincial policymakers, and patients were invited to participate. During this meeting, the prototypical program for reflex screening in Ontario was reviewed, and possible strategies for pilot testing and implementation were developed. Barriers and facilitators to implementation were discussed. The stakeholder meeting consisted of presentations by the study team, small and large group discussions, and guest speaker presentations. Group discussions were structured with representation from diverse specialties and various geographic locations to ensure that a range of stakeholder perspectives was represented. We utilized recommendations from the group discussion to further refine the proposed program for reflex LS testing in Ontario, ultimately resulting in the creation of the final framework. 


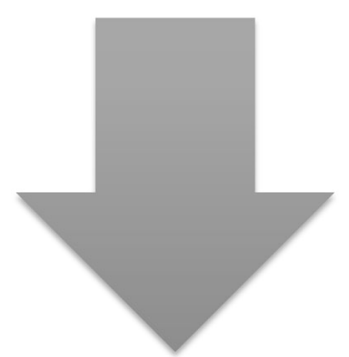

Top down approach

Mandate testing program at a policy or executive level first

Pro: speeds up

implementation process and

creates a widespread

standard of care.

Con: may be seen as authoritarian and met with resistance

Bottom up approach

Assess current culture of practice and adapt accordingly. Involve key stakeholders from the start regarding every step of the process. Pro: seen as inclusive and more likely to be adopted in the long term

Con: slower, longer and more complicated route (e.g.domino roll-out approach).

Fig. 1 Top-down versus bottom-up approach to program implementation.

\section{RESULTS}

\section{Participants}

We achieved data saturation after 26 interviews. This included interviews from 4 genetic counselors, 1 gynecologic oncologist, 11 pathologists, 6 provincial and national representatives, 2 surgeons, and 2 staff from the High Risk Ontario Breast Screening Program. The major themes we identified in the interviews were (1) ensuring consistency and quality of the final program, (2) education for multiple stakeholders, and (3) providing and sustaining adequate resources.

\section{Ensuring consistency and quality}

"Centralized oversight is the key component... if it all comes into Cancer Care Ontario, and that gets all the cancer reports, and all the cases of colorectal cancer and endometrial cancer under a certain age, you check to see, do they have the biomarkers done, if they didn't, you could do that centrally." Pathologist

"You should know right from the get-go how many sites you want to have doing the testing....you've got to get the data from them, that's the most important thing....because otherwise you don't know whether you are being successful or not." -Staff of Ontario Breast Screening Program

Participants identified that several centers within the province have already implemented LS testing; however, the challenge for provincial implementation of reflex testing will be to design and implement a provincial program with a standardized approach that is centrally administered and coordinated. Participants with a background in pathology described that to ensure consistency throughout the province, centralized oversight via a top-down approach was key. This refers to their recommendation that the program be mandated and monitored by an overall policy or at an executive level. To ensure program quality, participants, largely surgeons, also highlighted the idea of funding being tied in to overall quality metrics, and that a standardized reporting system should be mandated. Additional recommendations to ensure quality include ensuring access for rural patients. Finally, participants from the Ontario Breast Screening Program, based on their experience with breast cancer patients, proposed navigators at various levels, to ensure that patients move effectively through the system.

The majority of participants from all clinical groups identified that the top-down approach, while essential to ensure program consistency, should be balanced by a bottomup approach for program implementation, a process where stakeholders are involved in decision-making at the outset (Fig. 1).

\section{Education of multiple stakeholders}

"There has been more LS info available in the last 15 years but it's still not a household term by any means, and not a household term in medical fields either." - Pathologist

Participants from all clinical groups recognized that there was a need for education among all groups of health-care providers (primary care providers, surgeons, and pathologists) regarding appropriate screening recommendations, and information on how to educate LS patients and their relatives. The genetic counselors who participated in the study, as well as the other clinician participants, highlighted the important role that genetic counselors can play in not only the education of patients, but potentially also of health-care providers. Other strategies put forward included webinars, written material, as well as local champions as providers of education.

Participants identified that both patients and first-degree relatives also needed to be informed and educated about the implications of testing at the appropriate time during their care pathway. Participants felt that genetic counselors were perhaps the best equipped to counsel patients, yet currently, the surgeons in the study, for the most part, did not feel as if there was a clear algorithm to facilitate patients being seen by genetic counselors. Surgeons were identified as "gate-keepers" of the system and were identified as playing an important role in connecting patients with genetic counselors. The majority of participants emphasized that allowing flexibility regarding how genetic counselors were accessed (Skype, phone conversation, etc.) could potentially facilitate access to this group of individuals.

\section{Providing and sustaining multiple resources}

"The estimated cost for testing all colorectal cancers, endometrial cancers on patients under 70 ... years of age included BRAF and methylation ... there's going to be ... 900,000 dollars to a million dollars per year." - Pathologist

Participants, largely pathologists, expressed concern relating to how the costs associated with pathological testing of all index cases will be covered. In addition, there was concern with the cost of institutions shipping their pathology samples. Participants also highlighted that there are costs associated 


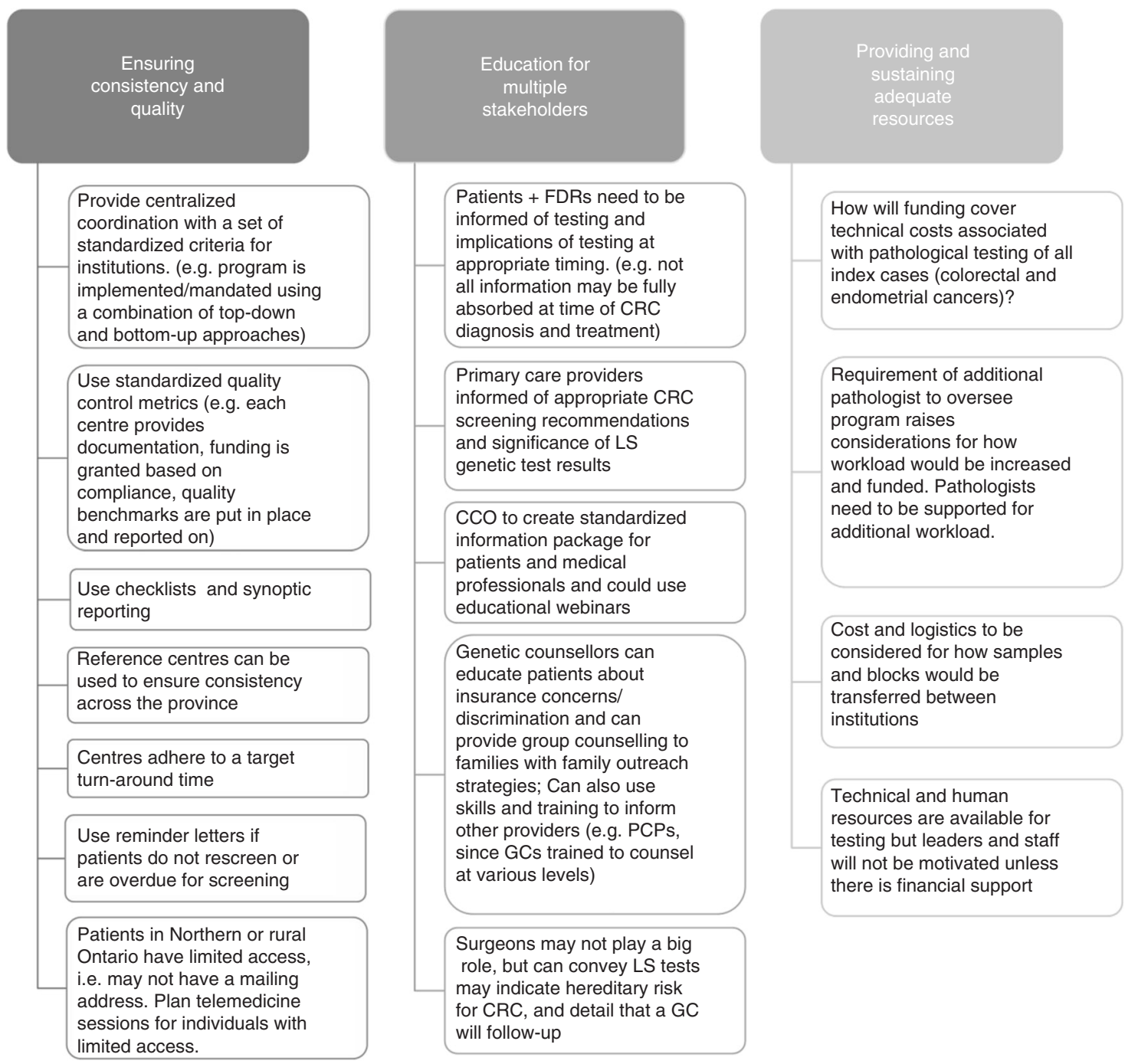

Fig. 2 Barriers and facilitators to implementing proposed Lynch syndrome testing pathway in Ontario. CCO Cancer Care Ontario, $C R C$ colorectal cancer, FDR first-degree relative, GC genetic counselor, $L S$ Lynch syndrome, $P C P$ primary care provider.

with increasing pathologists' workloads. This might necessitate either hiring additional pathologists or pathology technologists. Several participants discussed the potential for centralization to reduce the costs on the system, similar to how other biomarker programs have functioned.

These three themes provide an overview of the various factors that might challenge or facilitate successful implementation of a population-based reflex-testing program. They can be summarized as challenges with funding and resources, education of stakeholders across all disciplines, and ensuring consistency of reporting and interpretation of test results (Fig. 2).

\section{Implementation framework}

Based on these themes, a framework for a reflex LS testing program in Ontario was developed and presented at our stakeholder meeting for input. Thirty-six stakeholders attended the meeting ( 6 geneticists, 12 pathologists, 4 general surgeons, 1 gynecologic oncologist, 2 gastroenterologists, 2 family physicians, 1 national representative [Canadian Partnership Against Cancer], 8 provincial representatives [Ministry of Health and Long Term Care, and Cancer Care Ontario]). Stakeholders agreed with the overall framework as it was presented. Stakeholders, however, identified several potential issues, and made recommendations to facilitate both program implementation, as well as effective functioning of the program. These recommendations included navigation at various levels of the pathway, quality assurance standards, standardized reporting tools, education and training, and addressing issues of perceived insurance discrimination among patients. These recommendations were mapped to the appropriate stage of the framework (Fig. 3). In addition, stakeholders recommended that the pathway be restricted to patients under the age of 70 . This was largely due to the feasibility of managing the large number of CRC tumors for testing. The stakeholders were in agreement that they 


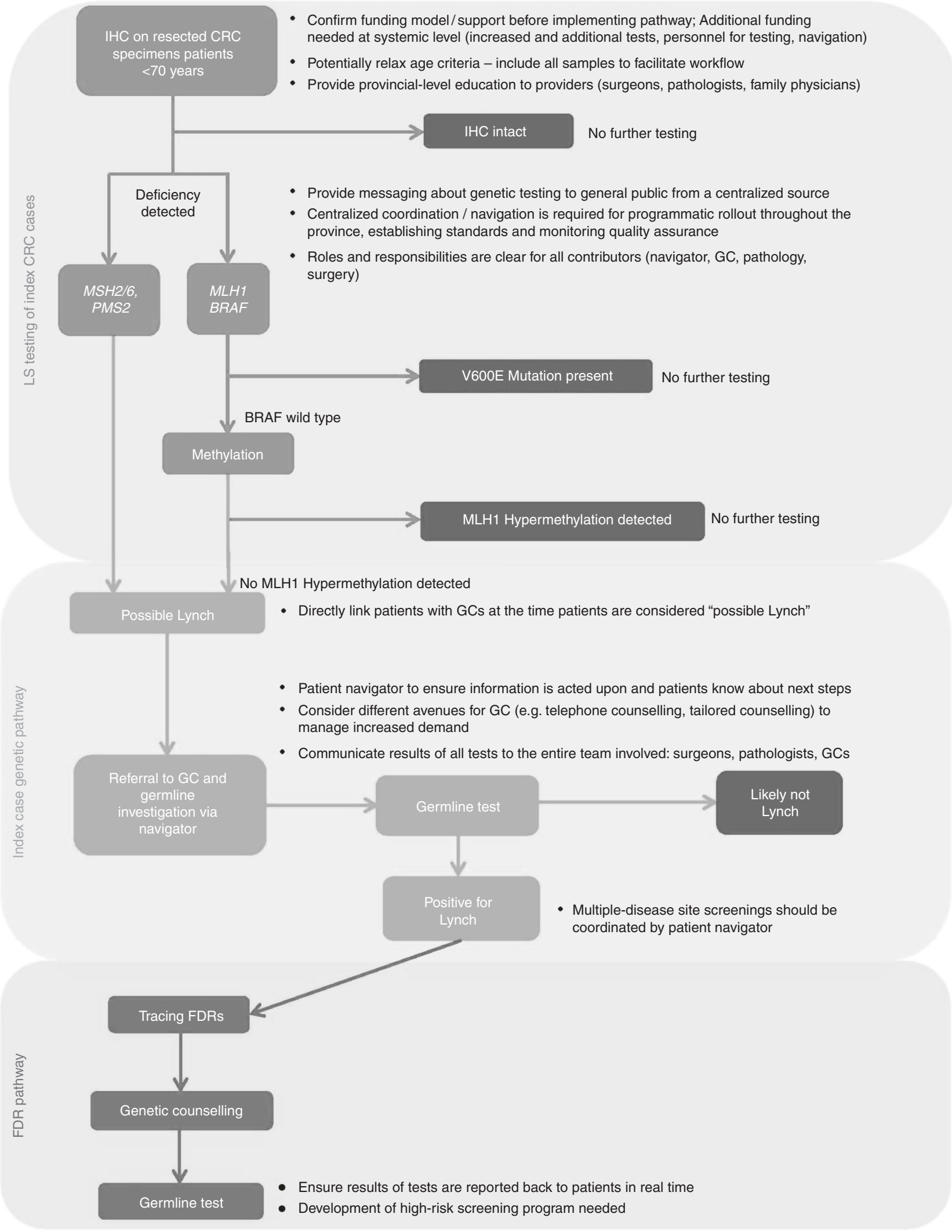

Fig. 3 Final framework for Lynch syndrome reflex testing in Ontario. CRC colorectal cancer, FDR first-degree relatives, GC genetic counselor, IHC immunohistochemistry, LS Lynch syndrome. 
Table 1 Summary of challenges, recommendations, and considerations for reflex testing in Ontario, by level

\begin{tabular}{|c|c|c|c|}
\hline Level & Challenges & Recommendations & Considerations/options \\
\hline Patient & $\begin{array}{l}\text { - Already dealing with cancer diagnosis } \\
\text { - Lack knowledge about Lynch syndrome } \\
\text { - Confusion, stress } \\
\text { - Family dynamics } \\
\text { - General concerns about genetic testing/ } \\
\text { implications }\end{array}$ & $\begin{array}{l}\text { - Education } \\
\text { - Communication } \\
\text { - Decision-making support } \\
\text { and resources } \\
\text { - Patient navigators } \\
\text { - Access to individual and } \\
\text { family psychosocial } \\
\text { counseling }\end{array}$ & $\begin{array}{l}\text { - Prepare patient version of the pathway and related material } \\
\text { that is transparent about testing, treatment, benefits/risks and } \\
\text { other implications } \\
\text { - Develop various types of information and decision support } \\
\text { (question prompt lines, decision aid, lay summary in different } \\
\text { languages) }\end{array}$ \\
\hline Provider & $\begin{array}{l}\text { - Range of providers to target (family } \\
\text { physicians, general surgeons, gynecologists, } \\
\text { oncologists, pathologists) } \\
\text { - Limited interest, knowledge } \\
\text { - General views about genetic implications } \\
\text { - Comfort with counseling role } \\
\text { - Practice variable at present } \\
\text { - Coordination, communication between } \\
\text { providers influences continuity of care }\end{array}$ & $\begin{array}{l}\text { - Education } \\
\text { - Communication } \\
\text { - Decision-making support } \\
\text { and resources }\end{array}$ & $\begin{array}{l}\text { - Prepare various versions or formats of the pathway and } \\
\text { accompanying instructions (full version, summary version, } \\
\text { pocket card, phone app) } \\
\text { - Frame as a beneficial service } \\
\text { - Work with professional societies to endorse pathway and } \\
\text { offer education services } \\
\text { - Develop continuing professional development module that } \\
\text { providers can complete } \\
\text { - Engage opinion leaders } \\
\text { - Establish regional or community level teams or networks } \\
\text { - Offer education/training for shared decision-making via } \\
\text { regional or community events } \\
\text { - Develop tools to help physicians offer decision-making } \\
\text { support }\end{array}$ \\
\hline System & $\begin{array}{l}\text { - Resources (extra testing, counseling) } \\
\text { - Infrastructure (information technology, } \\
\text { centralized pathology, coordination) } \\
\text { - Standardization } \\
\text { - Regional differences (equity of access- } \\
\text { geography, social determinants) }\end{array}$ & $\begin{array}{l}\text { - Itemize costs and } \\
\text { considerations for pathway } \\
\text { implementation } \\
\text { - Centralized navigation } \\
\text { - Training for navigator }\end{array}$ & $\begin{array}{l}\text { - Prepare policy brief for system-level decision-makers } \\
\text { - Explore option of provider reimbursement } \\
\text { - Generate job descriptions and competencies for patient } \\
\text { navigators }\end{array}$ \\
\hline Pathway & $\begin{array}{l}\text { - Standardization } \\
\text { - Timing of components, informed consent/ } \\
\text { opt-out } \\
\text { - Distinguish Lynch syndrome testing from } \\
\text { colorectal cancer screening }\end{array}$ & $\begin{array}{l}\text { - Central navigation to } \\
\text { ensure effective flow } \\
\text { - Review updated } \\
\text { pathways with experts }\end{array}$ & $\begin{array}{l}\text { - Have pathway reviewed and endorsed by various } \\
\text { professional organizations }\end{array}$ \\
\hline
\end{tabular}

perceived that testing the tumors of patients over the age of 70 would represent a significant cost to the system (both financial and time) with a low yield of new LS patients identified.

Participants at the stakeholder meeting identified challenges and possible strategies to mitigate these identified challenges, at various levels (patient, provider, system, and pathway) of the proposed reflex-testing pathway for LS. Challenges at the patient level included stressors related to a lack of knowledge about LS, implications of genetic testing, and concerns regarding individual family dynamics. Provider challenges related to the number and diversity of various providers to target (surgeons, family physicians, pathologists, etc.) and the range of interest and knowledge within and between the various groups. System challenges included concerns regarding resources and standardization across the province. Finally, challenges relating to the pathway itself included concerns regarding standardization and whether opt-out or informed consent would be required. Stakeholders highlighted that this could involve the use of various educational aides, liaising with professional societies to offer both pathway endorsement as well as formalized educational sessions. Finally, centralized navigation was also proposed as a means of ensuring effective flow through the program (Table 1).

\section{DISCUSSION}

This study describes the development of a program for reflex LS testing in Ontario. Key stakeholders identified several critical aspects to reflex-testing pathway success. These include ensuring consistency and quality of the program, educating multiple stakeholders, providing and sustaining multiple resources, and mapping out program logistics.

Ensuring the consistency and quality of the reflex-testing program was a frequent theme highlighted by our stakeholders as being essential for program success. This theme has also been highlighted in other work. For example, Bombard 
et al. identified that health-care providers feel that there is a lack of coordinated care for patients with possible LS, and that initiation of a provincial-wide reflex-testing pathway would help to standardize care. ${ }^{27}$ In a report of one institution's experience with reflex screening, barriers to compliance included a lack of consistency within the program. ${ }^{13}$ Other work assessing barriers and facilitators of implementing reflex testing found that a lack of consistency in guidelines regarding the management of LS patients was a significant barrier to implementation of reflex-testing programs. ${ }^{28}$ Ensuring that programs are developed using current guidelines, with the ability to deliver a consistent pathway through the system for patients regardless of their geographic location, is an important consideration in large-scale reflex-testing program development and implementation. This is especially true if individual institutions within a health-care system have differing ways of performing reflex testing locally. Communication, education, and top-down implementation are all strategies that will likely be required to ensure program consistency and quality.

The key informants in our study highlighted the importance of education, both at the patient and health-care provider level, as being essential to program success. Our interviewees indicated that programmatic educational interventions would need to include family physicians, pathologists, and general surgeons, but that educational interventions alone were unlikely to result in program implementation. ${ }^{29-31}$ Participants stated that a top-down approach, with a mandated program, would likely be necessary to ensure compliance, but to ensure long-term programmatic success this needed to be balanced with a bottom-up approach where long-term educational interventions are directed at specific users of the pathway. Our participants identified genetic counselors as playing a central role in patient education. They also highlighted that flexibility in how patients could access genetic counselors is an important consideration to ensure access for all patients, especially those located in more remote areas. Indeed, it has been shown that patients feel that remote counseling via genetic counselors is acceptable and informative. $^{32,33}$ Other programs have found higher rates of patient follow-through with genetic counseling and testing in institutions that have high levels of genetic counselor involvement. $^{12}$ While other work has similarly identified genetic counselors as playing a key educational role, our participants also highlighted the need for continuing medical education initiatives directed at health-care providers, specifically primary care providers as well as surgeons. These are important considerations in pathway development and implementation.

A central theme identified in our interviews was the need for adequate resources both to launch and operate the program. Cost-effectiveness studies have shown that the costs of a prototypical LS screening program would be similar to other existing screening programs. ${ }^{34,35}$ Snowsill et al. demonstrated that the additional costs required for surveillance were offset by the projected savings in cost for the treatment of patients who develop CRC. Moreover, in the United States, it is hypothesized that instituting a statewide reflex-screening program, rather than relying on single institutions, would be a way to potentially reduce cost, and improve the quality of patient care. ${ }^{36,37}$ Other work has found that cost uncertainties can act as barriers to implementing an effective reflexscreening pathway. ${ }^{28}$ Although ultimately data suggest that overall reflex testing is cost-effective on a population level, there would still be important costs to the system to both initiate and maintain a large-scale reflex-testing program. This is especially important to consider in light of the fact that many of our study participants advocated for components to the reflex-testing program that would incur significant costs such as adding navigators to the system, increasing access to genetic counselors, and increasing the workload for pathologists. Cost analysis implies that over the long run such programs are ultimately cost-effective; however, having adequate funds to initiate the program is an important consideration that could ultimately impact its feasibility.

The framework developed in this study reflects some of the considerations shown in other large-scale reflex-testing programs. Similar to the programs in Manitoba and Western Australia, our framework has age restrictions (with patients being included in these programs under age 70 and 60 respectively). ${ }^{14}$ Like the majority of these programs, IHC testing is one of the initial steps through the pathway. Finally, similar to the programs in Utah and Ohio, the Ontario framework plans to involve genetic counselors or navigators as early in the process as possible. ${ }^{14}$ Indeed, this was emphasized by the majority of our participants as being a central consideration for the future success of this program.

There are several limitations of this study. Although we had patient representatives at our stakeholder meeting, patients and their families were not interviewed. This was due to the fact that the qualitative interviews focused on system-level issues and concerns regarding resources necessary for pathway implementation. It is possible, however, that additional views from affected patients and their relatives would have been highlighted during the qualitative interviews and could have potentially informed the proposed design of the Ontario pathway. A second identified limitation of our study is that our key informants were predominantly from larger academic centers. Possibly, if there had been more representation from smaller centers, differing viewpoints or additional themes might have been identified. Finally, our study was directly relevant to implementation of reflex LS testing in a single province, and thus some of our study findings are reflective of the local context. These limitations notwithstanding, our findings include broad considerations that are applicable to other jurisdictions. Moreover, the methodology described in this study can be used as a framework by other organizations wishing to develop reflex-screening initiatives for other cancers. The final product is a prototype that can be utilized in other jurisdictions, taking into account local considerations. Importantly, this study highlights barriers, facilitators, and key themes that need to be considered. 
This study engaged multidisciplinary stakeholders in identifying program design and implementation approaches needed to overcome context-specific multilevel barriers relating to the implementation of a reflex-testing program for LS at a provincial level. Exploring these themes prior to program implementation is important to ensure success. This study highlights strategies to ensure stakeholder engagement, education, program quality, and accountability at a national level. We expect that results from this study will be applicable and relevant to decision-makers nationally and internationally who are looking to implement reflex-testing programs within their local context.

\section{ELECTRONIC SUPPLEMENTARY MATERIAL}

The online version of this article (https://doi.org/10.1038/s41436$018-0342-8)$ contains supplementary material, which is available to authorized users.

\section{ACKNOWLEDGEMENTS}

This study was conducted with the support of Cancer Care Ontario and the Ontario Institute of Cancer Research, through funding provided by the Government of Ontario and the Canadian Institutes for Health Research (FDN-148470). The authors acknowledge the assistance of Corrine Daly with this study.

\section{DISCLOSURE}

The authors declare no conflicts of interest.

\section{REFERENCES}

1. Canadian Cancer Society. Canadian cancer statistics 2016. http://www. cancer.ca/ /media/cancer.ca/CW/cancer\%20information/cancer\% 20101/Canadian\%20cancer\%20statistics/Canadian-Cancer-Statistics2016-EN.pdf?la=en. Accessed 11 April 2017

2. Matloff J, Lucas A, Polydorides AD, Itzkowitz SH. Molecular tumor testing for Lynch syndrome in patients with colorectal cancer. J Natl Compr Canc Netw. 2013;11:1380-1385.

3. Watson P, Vasen HFA, Mecklin J-P, et al. The risk of extra-colonic, extraendometrial cancer in the Lynch syndrome. Int J Cancer. 2008;123:444-449

4. Bonadona $\mathrm{V}$, Bonaïti $\mathrm{B}$, Olschwang $\mathrm{S}$, et al. Cancer risks associated with germline mutations in MLH1, MSH2, and MSH6 genes in Lynch syndrome. JAMA. 2011;305:2304-2310.

5. Morrison J, Bronner M, Leach BH, Downs-Kelly E, Goldblum JR, Liu X Lynch syndrome screening in newly diagnosed colorectal cancer in general pathology practice: from the revised Bethesda guidelines to a universal approach. Scand J Gastroenterol. 2011;46:1340-1348.

6. Palomaki GE, McClain MR, Melillo S, Hampel HL, Thibodeau SN. EGAPP supplementary evidence review: DNA testing strategies aimed at reducing morbidity and mortality from Lynch syndrome. Genet Med. 2009:11:42-65.

7. Hampel H, Stephens JA, Pukkala E, et al. Cancer risk in hereditary nonpolyposis colorectal cancer syndrome: later age of onset. Gastroenterology. 2005;129:415.

8. Liu T, Tannergård $P$, Hackman $P$, et al. Missense mutations in hMLH1 associated with colorectal cancer. Hum Genet. 1999;105:437-441.

9. Evaluation of Genomic Applications in Practice and Prevention (EGAPP) Working Group. Recommendations from the EGAPP Working Group: genetic testing strategies in newly diagnosed individuals with colorectal cancer aimed at reducing morbidity and mortality from Lynch syndrome in relatives. Genet Med. 2009;11:35-41.

10. Beamer LC, Grant ML, Espenschied CR, et al. Reflex immunohistochemistry and microsatellite instability testing of colorectal tumors for Lynch syndrome among US cancer programs and follow-up of abnormal results. J Clin Oncol. 2012;30:1058-1063.

11. Shaikh T, Handorf EA, Meyer JE, Hall MJ, Esnaola NF. Mismatch repair deficiency testing in patients with colorectal cancer and nonadherence to testing guidelines in young adults. JAMA Oncol. 2018:4:e173580.

12. Cragun D, DeBate RD, Vadaparampil ST, Baldwin J, Hampel H, Pal T. Comparing universal Lynch syndrome tumor-screening programs to evaluate associations between implementation strategies and patient follow-through. Genet Med. 2014;16:773-782.

13. Hill $A L$, Sumra KK, Russell MM, et al. A single institution experience in compliance with universal screening for Lynch syndrome in colorectal cancer. J Gastrointest Surg. 2015;19:543-550.

14. Palter VN, Baker N, Pollett A, et al. Learning by example: an international perspective on reflex-testing for Lynch syndrome. Ann Surg Oncol. (in press).

15. Cancer Care Ontario. Colorectal cancer screening. https://www. cancercare.on.ca/pcs/screening/coloscreening/?WT.mc_id=/ colorectalscreening. Accessed 11 April 2017.

16. Patton M. Qualitative evaluation and research methods. 2nd ed Newbury Park, CA: Sage; 1990.

17. Palinkas LA, Horwitz SM, Green CA, Wisdom JP, Duan N, Hoagwood K. Purposeful sampling for qualitative data collection and analysis in mixed method implementation research. Adm Policy Ment Health. 2015:42:533-544

18. Kuzel AJ, Sampling in Qualitative Inquiry. Doing Qualitative Research Edited by: Crabtree BF, Miller WL. 1999. Thousand Oaks, CA: SAGE publications. p31-35

19. Morse JM, Barrett M, Mayan M, Olson K, Spiers J. Verification strategies for establishing reliability and validity in qualitative research. Int J Qual Methods. 2002;1:13-22.

20. Daly C, Rotenberg C, Facey M, Baker N, Baxter NN. Reflex Lynch syndrome screening by example: a review of existing programs. J Clin Oncol. 2015;33 Suppl 3:abstr543.

21. Pope C, Ziebland S, Mays N Qualitative research in health care: analysing qualitative data. BMJ. 2000;320:414.

22. Braun V, Clarke V. Using thematic analysis in psychology. Qual Res Psychol. 2006;3:77-101.

23. Charmaz K Qualitiative interviewing and grounded theory analysis. In: Holstein JA, Gubrium JF, eds. Inside interviewing: new lenses, new concerns. SAGE publications, Thousand Oaks, CA. pg 310-311; 2001.

24. Corbin J, Strauss A Basics of qualitative research: techniques and procedures for developing grounded theory. 4th Ed. SAGE publications. Thousand Oaks, Ca. 2008.

25. Kvale S, Brinkman S. Interviews: learning the craft of qualitative interviewing. 2nd ed. Thousand Oaks, CA: SAGE Publications; 2009.

26. Tracy SJ. Qualitative quality: eight "big-tent" criteria for excellent qualitative research. Qual Inq. 2010;16:837-851.

27. Bombard $Y$, Rozmovits $L$, Sorvari $A$, et al. Universal tumor screening for Lynch syndrome: health-care providers' perspectives. Genet Med. 2016:11:1380.

28. Schneider JL, Davis J, Kauffman TL, et al. Stakeholder perspectives on implementing a universal Lynch syndrome screening program: a qualitative study of early barriers and facilitators. Genet Med. 2016:18:152-161.

29. Davis D, Galbraith R, American College of Chest Physicians Health and Science Policy Committee. Continuing medical education effect on practice performance: effectiveness of continuing medical education: American College of Chest Physicians Evidence-Based Educational Guidelines. Chest. 2009:135 3 Suppl:42S-48S

30. Davis D, O'Brien MA, Freemantle N, Wolf FM, Mazmanian P, TaylorVaisey A Impact of formal continuing medical education: do conferences, workshops, rounds, and other traditional continuing education activities change physician behavior or health care outcomes? Journal of the American Medical Association 1999:282:867-74.

31. Luchtefeld M, Kerwel TG. Continuing medical education, maintenance of certification, and physician reentry. Clin Colon Rectal Surg. 2012;25:171-176

32. Mette LA, Saldivar AMP, Poullard NE, et al. Reaching high-risk underserved individuals for cancer genetic counseling by videoteleconferencing. J Community Support Oncol. 2016;14:162-168.

33. Bradbury A, Patrick-Miller $L$, Harris $D$, et al. Utilizing remote real-time videoconferencing to expand access to cancer genetic services in 
community practices: a multicenter feasibility study. J Med Internet Res. 2016;18:e23.

34. Gudgeon JM, Williams JL, Burt RW, Samowitz WS, Snow GL, Williams MS. Lynch syndrome screening implementation: business analysis by a healthcare system. Am J Manag Care. 2011;17:e288-e300.

35. Ladabaum U, Wang G, Terdiman J, et al. Strategies to identify the Lynch syndrome among patients with colorectal cancer: a cost-effectiveness analysis. Ann Intern Med. 2011;155:69-79.
36. Cragun D, DeBate RD, Pal T. Applying public health screening criteria: how does universal newborn screening compare to universal tumor screening for Lynch syndrome in adults with colorectal cancer? J Genet Couns. 2015;24:409-420.

37. Bellcross CA, Bedrosian SR, Daniels $E$, et al. Implementing screening for Lynch syndrome among patients with newly diagnosed colorectal cancer: summary of a public health/clinical collaborative meeting. Genet Med. 2012;14:152-162. 